\title{
PENINGKATAN FASILITAS BAGI TAHFIZH ANAK USIA DINI “KUTTAB RUMAH QURAN” MENUJU PERSAINGAN PENDIDIKAN ANAK PRA SEKOLAH
}

\author{
Eko Aristanto1, Syarif Hidayatullah'2, Ike Kusdyah Rachmawati ${ }^{3}$, \\ Abdul Waris ${ }^{4}$, Khalikussabir ${ }^{5}$ \\ ${ }^{1}$ Universitas Merdeka Malang \\ email: Aristanto90@yahoo.co.id \\ Universitas Merdeka Malang \\ email: syarif_ok@yahoo.com \\ ${ }^{3}$ STIE Asia Malang \\ email: ike.kusdyah@gmail.com \\ ${ }^{4}$ Politeknik Negeri Malang \\ korespondensi email: waris_sip@yahoo.com \\ ${ }^{5}$ Universitas Islam Malang \\ email: khalikussabir_fe@unisma.ac.id
}

\begin{abstract}
Tahfizh Anak Usia Dini Kuttab Rumah Quran (TAUD KRQ) is an educational institution that concentrates on educating Quran from the early age. TAUD is a tahfidz program for the 3-6 years old children, enjoyable activities with the Quran is the approach. The expectation of this program is they would have kind of passion and good at memorizing the Quran, so that one day he would become Hamilul Quran, Insya Allah. TAUD KRQ in its implementation to create hafiz (memorizers) of the Quran ideally should have learning facilities and a balanced playing considering TAUD students are the early childhood who are still love to play. To achieve these ideal conditions, TAUD KRQ requires the cooperation from various parties. The reforms that must be equipped to achieve goals are the improvement of indoor and outdoor learning facilities, information media and motivational instructor. By the Observation, Survey, consultation, training, discussion, and direct practice method, the results of community service activities are as follows: 1) Issues the aspects of outdoor facilities are assisted by repairing playgrounds, building condition with colors that match as bright and colorful, 2) Issues of Indoor facilities are assisted with the provision of Learning Media like 2 pieces of magnetic blackboard, printers, puzzle games, 20 writing tables and puzzle rugs to play on the floor. 3) Issues human resources are assisted by conducting motivational training for administrators and teachers, 4) Issues of marketing are assisted by creating a Blog.
\end{abstract}

Keywords: tahfizh; indoor facilities; motivation

\begin{abstract}
ABSTRAK
Tahfizh Anak Usia Dini Kuttab Rumah Quran (TAUD KRQ) adalah lembaga pendidikan yang fokus mendidik Alquran sejak usia dini. TAUD adalah program tahfidz untuk anak usia 3 - 6 tahun. Konsepnya adalah aktivitas menyenangkan bersama Quran. Harapannya agar Ananda mencintai dan terbiasa menghafal Al-
\end{abstract}


Quran, sehingga kelak menjadi hamilul Quran, insya Allah. TAUD Kuttab Rumah Quran dalam pelaksanaannya untuk menciptakan para hafiz (penghafal) alquran idealnya memiliki fasilitas belajar dan bermain yang seimbang mengingat siswa TAUD adalah anak usia dini yang masih senang akan bermain. Untuk mencapai kondisi ideal tersebut TAUD Kuttab Rumah Quran membutuhkan kerjasama dari berbagai pihak. Adapun pembenahan yang harus dilengkapi untuk mencapai kondisi ideal tersebut seperti perbaikan fasilitas belajar indoor dan outdoor serta media informasi dan motivasi pengajar. Dengan Metode Observasi, Survey, konsultasi, pelatihan, diskusi dan metode praktek langsung diperoleh Luaran kegiatan pengabdian kepada masyarakat ini adalah berupa: 1) Masalah Aspek fasilitas outdoor dibantu dengan melakukan perbaikan taman bermain, tempat bermaian, tampilan gedung dengan pengecatan dengan warna yang sesuai warna cerah dan warna warni, 2) Masalah Fasilitas indoor dibantu dengan pengadaan Media Pembelajaran berupa papan tulis magenetik 2 buah, printer, puzzle games, meja tulis duduk 20 buah serta karpet puzzle untuk bermain dilantai. 3) Masalah SDM dibantu dengan melakukan pelatihan motivasi kepada pengurus dan guru, 4) Masalah Pemasaran dibantu dengan pembuatan Blog.

Kata Kunci: tahfizh; fasilitas indoor; motivasi

\section{PENDAHULUAN}

Kelurahan Lowokwaru Kota Malang memiliki 15 RW (Rukun Warga) dan 104 RT (Rukun Tetangga) secara administratif Lowokwaru dikelilingi oleh beberapa kelurahan lain yang ada di Kota Malang. Sebelah utara, Lowokwaru berbatasan dengan Kelurahan Tulusrejo, di sebelah timur, kelurahan berbatasan dengan Kelurahan Purwantoro, di sebelah selatan berbatasan dengan Kelurahan Saman, dan di sebelah barat berbatasan dengan Kelurahan Penanggungan. Dalam menjalankan tugasnya pemerintahan Kelurahan Lowokwaru memiliki beberapa mitra kerja. Mulai dari bidang ekonomi masyarakat, bidang pendidikan, keamanan dan ketertiban, kesehatan masyarakat, partisipasi masyarakat, pemerintahan, lembaga masyarakat, hingga pemberdayaan keluarga. Selain itu, ada organisasi sosial kemasyarakatan seperti karang taruna, karang werda, kader lingkungan, PSM (Pekerja Sosial Masyarakat), Gapoktan (Gabungan Kelompok Tani dan Nelayan), KKB (Kader Keluarga Berencana), BKB (Bina Keluarga Balita), WKSBM (Wahana Kesejahteraan Sosial Berbasis Masyarakat), Tokoh Masyarakat, Gerdu Taskin, PLKB, Dasawisma, PAUD (Pendidikan Anak Usia Dini), TK, Modin, Satgas Linmas, dan lain-lain. Untuk mendukung misi Kota Malang sebagai salah satu kota pendidikan di Jawa Timur, pendidikan juga digalakkan di Kelurahan Lowokwaru.Dari data yang ada Dinas Pendidikan Kota Malang tahun 2019, Daftar satuan pendidikan (sekolah) anak usia dini diKecamatan Lowokwaru berjumlah 196 yang terdiri atas satuan Kelompok Bermaian (KB), POS PAUD, RA/BA/TA, TK, dan TPA. Dari data tersebut belum ada data terkait lembaga yang mengajarkan secara khusus mendalami al quran seperti Kuttab Rumah Quran (KRQ).

Tahfizh Anak Usia Dini Kuttab Rumah Quran (TAUD KRQ) adalah lembaga pendidikan yang fokus untuk mendidik Alquran sejak usia dini. TAUD 
adalah program tahfidz untuk anak berusia 3 - 6 tahun (Azmil Hashim \& Ab.Halim Tamuri, 2012). Konsepnya adalah aktivitas belajar menyenangkan bersama Quran. Harapannya agar anak-anak usia dini mencintai dan terbiasa menghafal Al-Quran, sehingga diharapkan menjadi hamilul Quran, insya Allah. TAUD Kuttab Rumah Quran merupakan sebuah lembaga pendidikan fleksi schoolling yang memiliki misi utama menanamkan 3 hal inti kepada anak sebagai pondasi. Pondasi ini sangatlah penting bagi perkembangan anak hingga masa dewasa kelak. Pondasi ini adalah menanamkan al-quran, menanamkan cinta hadits dan membiasakan akhlak.

TAUD KRQ didirikan oleh Abu Khodijah Ricki Kurniawan, dan Ummu Asla Suwarti pada tahun 2016 yang dalam pelaksanaannya untuk menciptakan para hafiz (penghafal) alquran idealnya memiliki fasilitas belajar dan bermain yang seimbang mengingat siswa TAUD adalah anak usia dini yang masih senang akan bermain. Untuk mencapai kondisi ideal tersebut TAUD Kuttab Rumah Quran membutuhkan kerjasama dari berbagai pihak. Adapun pembenahan yang harus dilengkapi untuk mencapai kondisi ideal tersebut seperti perbaikan fasilitas belajar indoor dan outdoor serta media informasi dan motivasi pengajar.

Adapun permasalahan TAUD Kuttab Rumah Quran yang disusun berdasarkan kebutuhan prioritas mitra TAUD Kuttab Rumah Quran adalah 1) Aspek Proses Pembelajaran: Dalam proses pembelajaran ada dua fasilitas yang mendukung proses pembelajaran yaitu fasilitas outdoor (taman bermain, tempat bermain serta tampilan gedung) dan berikutnya adalah fasilitas indoor (media pembelajaran dalam gedung seperti papan tulis, alat bermaian, meja belajar serta alat permaianan yang menarik). Media proses Pembelajaran yang digunakan masih sedikit \& terbatas. Media proses pembelajaran yang digunakan saat ini masih terbatas dengan media seadanya padahal tempat ini merupakan tempat awal pencetak hafiz penghapal al quran dan peserta yang ada masih belia sehingga sangat dibutuhkan media pembelajaran yang nyaman dan menyenangkan (Dimyati \& Mudjiono, 2009). Walau masih terbatasnya media pembelajaran hal ini tidak mengecilkan semangat belar dan mengajar di TAUD "Kuttab Rumah Quran", namun dengan adanya bantuan media pembelajaran yang baik dan menyenangkan diharapkan semangat belajar siswa dan motivasi mengajar guru menjadi meningkat (Nurseto, 2012), 2) Aspek Sumberdaya Manusia, skill atau kemampuan yang terbatas karena kemampuan tenaga kerja dalam menggunakan fasilitas yang masih terbatas, sehingga dibutuhkan pelatihan motivasi bagi guru dan tenaga administasi lainnya dengan harapan dapat meningkatkan ketrampilan dalam sistem mengajar yang menarik pada TAUD "Kuttab Rumah Quran" (Zaman \& Eliyawati, 2010). 3) Aspek Manajemen Pemasaran, belum ada Penerapan strategi pemasaran yang tepat sehingga TAUD "Kuttab Rumah Quran" masih terbatas dikenal dilingkungan kelompok dan pengajian serta daerah Kelurahan Lowokwaru saja. Sistem pemasaran sudah menggunakan media sosial seperti Facebook, WA, Email dan IG namun cara ini saja masih dirasa kurang cukup 
untuk menjangkau secara luas pemasaran dan pengenalan TAUD "Kuttab Rumah Quran". Dibutuhkan manajemen Pemasaran dengan penguasaan teknologi informasi yang tepat untuk menjangkau perluasan pasar. Baik pemasaran off line maupun online. Adanya pelatihan web online diharapkan dapat meningkatkan perluasan pasar (Fuad \& Ghufron, 2014) (Kurniawati, Santoso, \& Widowati, 2019), Dari permasalahan tersebut TAUD Kuttab Rumah Quran masih memerlukan bantuan fisik dan non fisik untuk menguatkan perencanan bisnis yang dibuat oleh mitra Kegiatan ini secara nyata dapat diwujudkan dalam pendekatan Pengembangan (Hakim, 2014). Dengan tujuan: 1) Pengoptimalan pengembangan usaha TAUD "Kuttab Rumah Quran" melalui pendekatan pemberdayaan masyarakat khususnya Usaha Kecil dan Menengah (UKM) bidang Pendidikan untuk dapat meraih peluang usaha sekaligus diversifikasi produk melalui bantuan perbaikan dan pengadaan prasarana dan sarana (Taufiq Akbar, Indah Mindarti, \& Hadi, 2014), 2) Meningkatnya motivasi dan ketrampilan dalam pengelolaan bisnis pada mitra TAUD "Kuttab Rumah Quran".

\section{METODE PELAKSANAAN}

Metode kegiatan pengabdian masyarakat yang dilakukan disesuaikan dengan kondisi dan intervensi yang akan dilakukan. Secara umum kegiatan ini dilaksanakan dengan menggunakan metode ceramah, diskusi, demonstrasi, praktik langsung, serta observasi (Rachmawati, Isvandiari, Andini, \& Hidayatullah, 2018) (Hidayatullah, Windhyastiti, Aristanto, Khouroh, \& Kusdyah, 2019). 1) Metode diskusi, digunakan sebagai media komunikasi saat pelatihan berlangsung sehingga terjadi komunikasi dua arah antara pemateri dan Guru dan Pengurus TAUD, 2) Metode praktik langsung, digunakan untuk mengatasi permasalahan secara langsung seperti perbaikan fasilitas indoor dan outdoor yang ada, tentunya dengan koordinasi bersama. 3) Metode observasi, dilakukan untuk mengamati fasilitas indoor dan outdoor TAUD "Kuttab Rumah Quran" 4) Sosialisasi: Survey awal sekaligus pengenalan kepada mitra, bahwa tim PKM memiliki program untuk peningkatan ekonomi terutama ditujukan pada TAUD "Kuttab Rumah Quran". 5) Konsultasi, Untuk mengetahui permasalahan utama dari TAUD "Kuttab Rumah Quran", Konsultasi ditujukan untuk menggali akar permasalaan dalam menentukan solusi dari aspek pasar \& pemasaran, aspek produksi, aspek manajemen, aspek SDM sehingga mitra mengetaui, memahami dan dapat menentukan solusi permasalahan. 6) Penyuluhan, untuk meningkatkan kapasitas tempat, pengembangan fasilitas tempat baik indoor maupun outdoor dan penambahan pengetahuan tentang teknologi informasi dan aspek pemasaran dengan pembuatan blog TAUD. 7) Pelatihan, ditujukan agar mitra memiliki keahlian (skill) dari aspek kegiatan usaha yang belum terpecahkan solusinya pada pendekatan konsultasi. Dalam pendekatan ini dilakukan setelah penentuan masalah yang membutuhkan tindak lanjut pelatihan dari hasil konsultasi terhadap semua aspek aktifitas usaha (Nurhayati \& Rakhman, 2017) (Kasrani, 
2016). Metode tersebut disebut problem solving Program ini telah dilaksanakan sejak bulan Juni Tahun 2019. Kegiatan umum yang dilakukan antara lain 1). Sosialisasi akan diadakan program PKM pada mitra TAUD 'Kuttab Rumah Quran",2). Peninjauan lokasi tempat mitra, 3). Identifikasi kebutuhan mitra serta wawancara awal dengan mitra, 4) perbaikan fasilitas outdoor TAUD 'Kuttab Rumah Quran", 5) pemesanan kebutuhan indoor buat TAUD.

\section{HASIL DAN PEMBAHASAN}

Hasil dari Pengabdian yang dilakukan Tim PKM (Program Kemitraan Masyarakat) di fokuskan pada permasalahan yang ada pada mitra:

1. Masalah Fasilitas outdoor (taman bermain): Tim pengabdi melakukan Perbaikan Taman bermain TAUD “Kuttab Rumah Qiran” yang sebelumnya tanah dibantu pemgecoran dengan semen agar peserta didik TAUD dapat lebih nyaman bermain (tidak kotor).

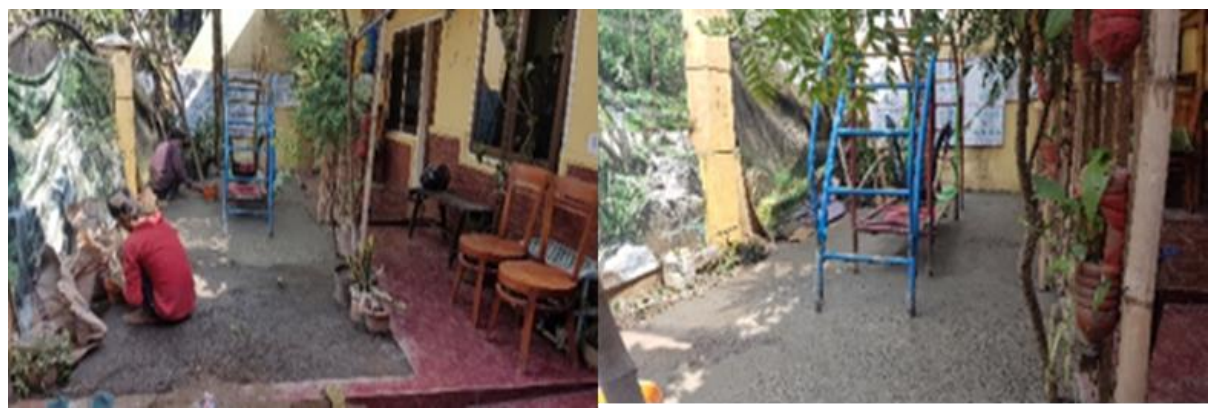

Gambar 1. Perbaikan Taman

2. Masalah Fasilitas outdoor (tempat bermain): Tim pengabdi melakukan Perbaikan Tempat bermain yang sebelumnya kusam di cat ulang dengan motif warna-warni agar anak peserta TAUD menjadi senang bermain.

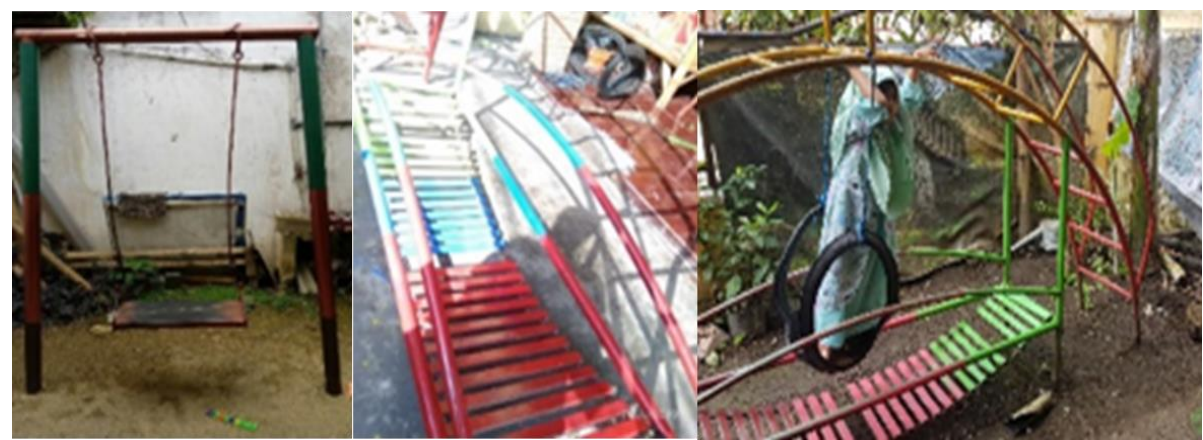

Gambar 2. Pekerjaan perbaikan tempat bermain

3. Masalah Fasilitas outdoor (tampilan gedung): Tim pengabdi melakukan Pengecatan Gedung TAUD: Gedung TAUD selama ini memiliki tampilan cat rumah seperti pada umumnya, hal ini membuat nuansa TAUD tidak 
seperti nuansa sekolah anak usia dini. Setelah berkonsultasi dengan pengelola TAUD menghendaki adanya pewarnaan yang membuat siswa TAUD senang dengan cat warna warni.

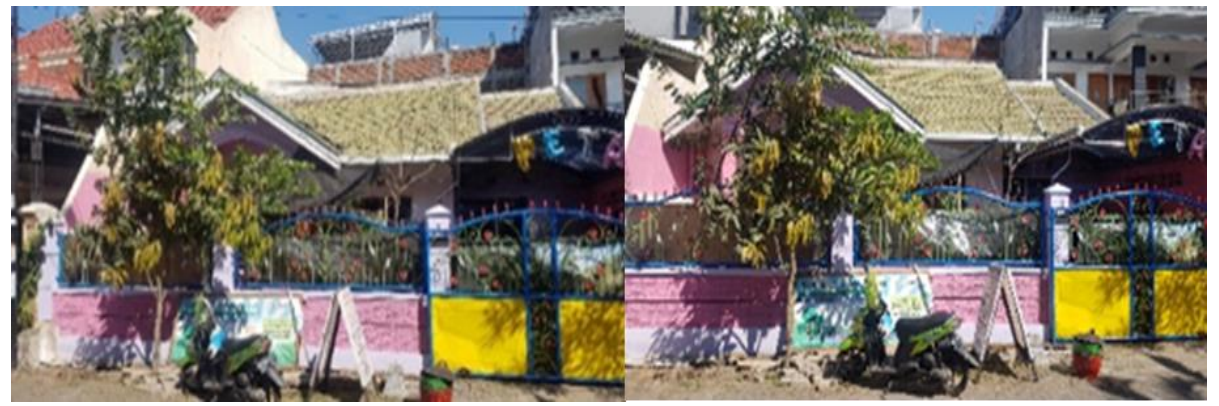

Gambar 3. Tampilan gedung TAUD yang baru

4. Masalah media pembelajaran: Tim pengabdi membantu pengadaan media pembelajaran seperti: Papan Tulis Magnetik, printer, meja belajar duduk, serta Learning Arabic for Quranic Understanding (LAQU), membuat system pelajaran lebih variatif (Vitianingsih, 2016).

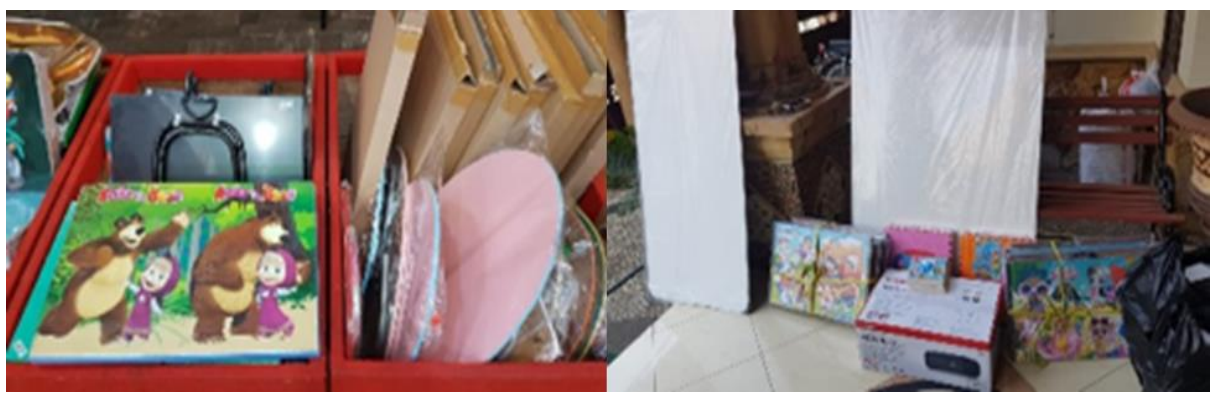

Gambar 4. Bantuan Fasilitas Indoor

5. Masalah SDM: Tim pengabdi melakukan Penyuluhan \& pelatihan yang berkelanjutan. Penyuluhan motivasi, pelatihan pembuatan web-online bagi pengelola TAUD.

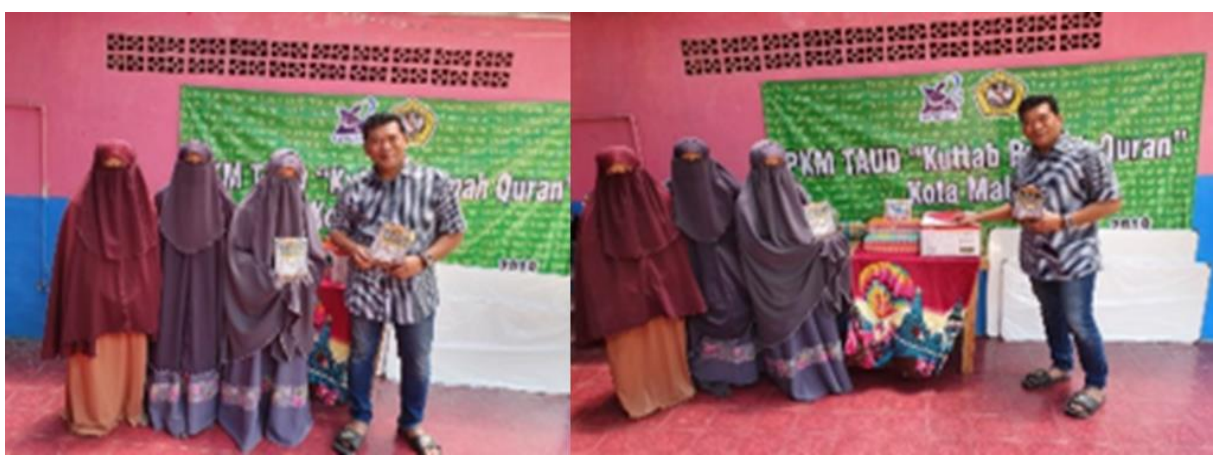

Gambar 5. Pelatihan SDM 
6. Masalah Pemasaran: Pada saat diskusi dan penyuluhan Tim pengabdi juga menemukan masalah pemasaran dari TAUD khususnya secara online, dari masalah tersebut untuk meningkatkan jumlah siswa dan informasi pemasaran secara online TAUD dibuatkan media pemasaran online TAUD dengan nama https://kuttabrumahquran.blogspot.com/

Sistem pembelajaran pada TAUD sangat berbeda dengan sekolah atau pendidikan pada umumnya, karena khusus untuk anak usia dini dapat membaca dan menghafal alquran. Sehingga system AMALI (Alami, Mainkan, Aplikasikan, Lagukan, dan Imajinasikan) masih sangat dibutuhkan. Media pembelajaran adalah satu dari sekian jenis sarana pendidikan yang digunakan sekolah. Secara garis besar, media pembelajaran merupakan alat bantu proses dalam kegiatan belajar mengajar yang digunakan untuk merangsang pikiran, atensi, perasaan, hingga keterampilan belajar siswa (Heinich, R., Molenda, M., Russell, J., \& Smaldino, 1999). Demikian halnya dengan TAUD Kuttab Rumah Quran, dimana dalam transfer keilmuan agama masih sangat dibutuhkkan media pembelajaran yang mendukung. Untuk mendukung hal tersebut sangat dibutuhkan dukungan lingkungan internal maupun eksternal serta pengadaan perbaikan fasilitas indoor maupun outdoor sehingga setelah pemberian bantuan oleh tim PKM Unmer Malang diharapkan 1. Orang tuan yang akan menyekolahkan anaknya di TAUD semakin banyak sehingga penghafal al quran juga semakin banyak 2. Informasi tentang TAUD semakin luas dengan adanya media blog dan banner yang ditempatkan di pinggir jalan, 3. Lingkungan TAUD semakin asri dengan pengecatan yang berwarna warni pagar, tembok dan tempat bermain, 4. Media pembelajaran akan semakin lengkap dan nyaman sehingga peserta didik akan merasa nyaman berada di TAUD.

\section{KESIMPULAN}

Kesimpulan dalam kegiatan ini adalah Kuttab Rumah Quran Kota Malang membutuhkan sentuhan bantuan dari berbagai pihak untuk pengembangan fasilitas indoor maupun outdoor. Tim Pengabdi dari Universitas Merdeka Malang yang mendapatkan hibah PKM (Program Kemitraan Masyarakat) setidaknya dapat meringankan masalah yang dihadapi seperti: 1) Masalah Aspek fasilitas outdoor dengan menggunakan metode observasi dan praktek langsung dibantu dengan melakukan perbaikan taman bermain, tempat bermaian, tampilan gedung dengan pengecatan dengan warna yang sesuai warna cerah dan warna warni, 2) Masalah Fasilitas indoor dengan menggunakan metode observasi dan praktek langsung dibantu dengan pengadaan Media Pembelajaran berupa papan tulis magenetik 2 buah, printer, puzzle games, meja tulis duduk 20 buah serta karpet puzzle untuk bermain dilantai. 3) Masalah SDM dengan menggunakan metode penyuluhan dan pelatihan dibantu dengan melakukan pelatihan motivasi kepada pengurus dan guru, 4) Masalah Pemasaran dengan menggunakan metode diskusi dan konsultasi dibantu dengan pembuatan Blog https://kuttabrumahquran .blogspot.com dan pelatihan bagaimana mengisi blog yang menarik. 


\section{UCAPAN TERIMA KASIH}

Ucapan terimakasih yang sebesar-besarnya kami sampaikan pada beberapa pihak antara lain:

1. Kementerian Ristekdikti yang telah memberikan kesempatan kepada pengabdi untuk mengaplikasikan ide pengabdian pada TAUD Kuttab Rumah Quran Kota Malang.

2. LPPM Universitas Merdeka Malang yang senentiasa support dengan kegiatan Penelitian dan pengabdian.

3. TAUD Kuttab Rumah Quran Kota Malang.

Semoga sehat dan sukses beserta kita semuanya. Aamin

\section{DAFTAR RUJUKAN}

Azmil Hashim, \& Ab.Halim Tamuri. (2012). Persepsi Pelajar Terhadap Kaedah Pembelajaran Tahfiz al-Quran di Malaysia. Journal of Islamic and Arabic Education, 4(2), 1-10. Retrieved from http://journalarticle.ukm.my/5990/1/43.pdf

Dimyati \& Mudjiono. (2009). Konsentrasi Belajar. Kesehatan Mental.

Fuad, M., \& Ghufron, A. (2014). Pengembangan Program CAI Dalam Pembelajaran PAI Materi Haji dan Umrah Untuk Siswa Madrasah Tsanawiyah. Jurnal Inovasi Teknologi Pendidikan, 1(1), 84-97. https://doi.org/https://doi.org/10.21831/tp.v1i1.2461

Hakim, R. (2014). Pembentukan Karakter Peserta Didik Melalui Pendidikan Berbasis Al-Quran, 4(2), 123-136. https://doi.org/10.21831/jpk.v0i2.2788

Heinich, R., Molenda, M., Russell, J., \& Smaldino, S. (1999). Instructional media and technologies for learning. (6th ed.). University of Georgia.

Hidayatullah, S., Windhyastiti, I., Aristanto, E., Khouroh, U., \& Kusdyah, I. (2019). PKM Kopi Rakyat Kelompok Wanita Tani (KWT) "Ngudi Rahayu" Desa Kebobang Wonosari Kabupaten Malang. (JAPI) Jurnal Akses Pengabdian Indonesia, 4(1), 130-136. https://doi.org/http://dx.doi.org/10.33366/japi.v4i2.1583

Kasrani. (2016). Evaluasi Program Pendidikan Anak Usia Dini (Paud). Manajemen Pendidikan, 25(2), 233-243.

Kurniawati, E., Santoso, A., \& Widowati, S. Y. (2019). Pelatihan Pemasaran Online Bagi Kelompok Usaha Bersama (KUB) "SRIKANDI". Jurnal Inovasi Hasil Pengabdian Masyarakat (JIPEMAS), 2(2), 132-138. https://doi.org/10.33474/jipemas.v2i2.2722

Nurhayati, S., \& Rakhman, A. (2017). Studi Kompetensi Guru Paud Dalam Melakukan Asesmen Pembelajaran Dan Perkembangan Anak Usia Dini Di Kota Cimahi. Jurnal Pendidikan Anak, 6(2), 109-120. https://doi.org/10.21831/jpa.v6i2.17699

Nurseto, T. (2012). Membuat Media Pembelajaran yang Menarik. Jurnal Ekonomi Dan Pendidikan, 8(1), 19-35. https://doi.org/10.21831/jep.v8i1.706 
Rachmawati, I. K., Isvandiari, A., Andini, T. D., \& Hidayatullah, S. (2018). PKM. Peningkatan Usaha Jamu Saritoga Ukm "Prayogo" dan Karang Taruna "Bhakti" Dusun Lopawon Desa Kebobang Wonosari Kabupaten Malang. JAPI (Jurnal Akses Pengabdian Indonesia), 3(2), 70-76. https://doi.org/10.33366/japi.v3i2.1016

Taufiq Akbar, M., Indah Mindarti, L., \& Hadi, M. (2014). Upaya Pemberdayaan Usaha Kecil Menengah (UKM) Industri Krupuk Rengginang. Jurnal Administrasi Publik (JAP), 2(11), 1-7.

Vitianingsih, A. V. (2016). Game Edukasi Sebagai Media Pembelajaran Pendidikan Anak Usia Dini. Jurnal Inform, 1(1), 1-8. https://doi.org/http://dx.doi.org/10.25139/ojsinf.v1i1.220

Zaman, B., \& Eliyawati, C. (2010). Bahan Ajar PPG. Media Pembelajaran Anak Usia Dini. Universitas Pendidikan Indonesia. 